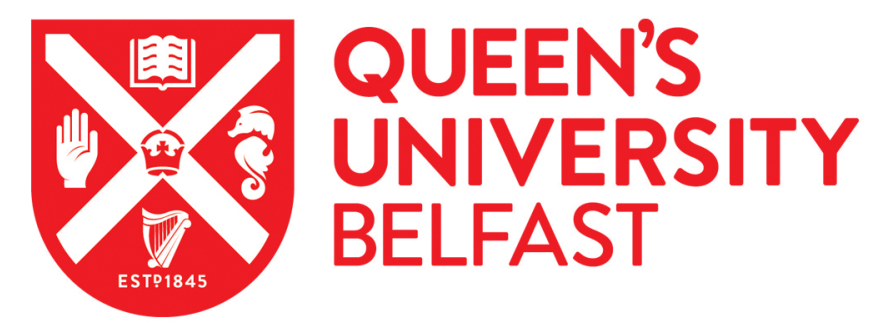

\title{
Methods to enhance the performance of a 3D coastal wave basin
}

O'Boyle, L., Elsaesser, B., \& Whittaker, T. (2017). Methods to enhance the performance of a 3D coastal wave basin. Ocean Engineering, 135, 158-169. https://doi.org/0.1016/j.oceaneng.2017.03.006

\author{
Published in: \\ Ocean Engineering
}

Document Version:

Peer reviewed version

Queen's University Belfast - Research Portal:

Link to publication record in Queen's University Belfast Research Portal

\section{Publisher rights}

Copyright Elsevier 2017.

This manuscript has been distributed under a Creative Commons Attribution-NonCommercial-NoDerivs License

(https://creativecommons.org/licenses/by-nc-nd/4.0/), which permits distribution and reproduction for non-commercial purposes, provided the author and source are cited.

\section{General rights}

Copyright for the publications made accessible via the Queen's University Belfast Research Portal is retained by the author(s) and / or other copyright owners and it is a condition of accessing these publications that users recognise and abide by the legal requirements associated with these rights.

Take down policy

The Research Portal is Queen's institutional repository that provides access to Queen's research output. Every effort has been made to ensure that content in the Research Portal does not infringe any person's rights, or applicable UK laws. If you discover content in the Research Portal that you believe breaches copyright or violates any law, please contact openaccess@qub.ac.uk. 
* corresponding author (louise.oboyle@qub.ac.uk)

\section{Abstract}

7 Following completion of a new $18 \mathrm{~m}$ by $16 \mathrm{~m}$ 3D coastal wave basin facility by Queen's University

8 Belfast in 2010, efforts to assess and enhance the performance were undertaken. A combined

9 physical and numerical modelling methodology was employed. Key findings are presented which should benefit others using or developing such facilities. Physical mapping was carried out using a specially developed polychromatic wave packet allowing accurate and efficient mapping of multiple frequencies simultaneously. Numerical modelling was undertaken using a phase resolving coastal wave propagation model to determine causes of observed non-homogeneity in the wave basin and efficiently determine an optimum wave basin design. Lateral absorption implemented along the side walls of the basin as a result of this work has significantly improved the homogeneity of the wave climate with little reduction to the total energy in the main working area. The shape of transition panels provided between the wave paddles and side beaches have been optimised using the wave propagation model. These developments have resulted in a wave basin which is significantly improved in terms of wave climate variability and energy absorption. 


\section{Introduction}

Laboratory wave generation and wave basin experimentation are invaluable within the fields of coastal engineering and naval architecture. Even taking into consideration the recent progress in computing and numerical modelling capabilities, physical modelling remains a critical step for numerical modelling validation. However, no wave basin is perfect. Variations in the wave climate within a basin are to be expected due to interactions with the wave-maker and beaches. On the other hand there is an increase in the levels of precision required from physical testing in wave basins. Traditionally the use of wave basins for modelling harbours, ports breakwaters, offshore structures and early stage marine renewable device development has primarily focused on matching statistical properties such as significant wave height and mean wave period at a single point in the basin, i.e. the model location. Where the area of interest covers a number of points within the basin (e.g. WEC array studies) a different approach is required. In this case the variation in amplitude of each frequency component within the entire area of interest should be quantified and understood. Therefore it is desirable to minimise variations in wave climate as much as practically possible.

Reflection of wave energy from wave tank boundaries and model structures, which are re-reflected from tank boundaries, is one of the most common effects influencing the accuracy of laboratory experiments. Unless these reflections are accounted for in the experimental analysis, they are undesirable and can mask real effects, contaminating experimental results. To ensure high quality experimental results, particularly where physical measurements are required for validation of numerical models, wave energy absorption is one of the most important parameters to control in the tank.

Two dimensional wave tanks (or wave flumes) commonly consist of a straight channel with a wavemaker at one end and an absorbing beach at the other. A review of developments in wave-maker theory is given by Dean and Dalrymple (1991) and Hughes (1993). In a good quality facility there 
47 should be minimal spatial variability in the wave field, aside from evanescent waves which occur due to the mechanical wave generation in addition to the propagating wave and exist very close to the wave-maker (Dean and Dalrymple, 1991). Therefore the wave field can be characterised using reflection analysis (e.g. Mansard and Funke, 1980). This allows separation of the incident and reflected wave spectra assuming the surface elevation measured at a particular point is the summation of these two components travelling in opposite directions to each other.

Three dimensional wave generation is more complex. This requires the use of multi-unit, directional wave-makers which move in a snake like action to generate long crested waves at oblique angles to the wave-maker and multidirectional short crested seas. Directional wave-makers are also usually installed along one side of the basin only, meaning that oblique waves will at some point approach the side walls of the basin. This can be dealt with in a number of ways for example by providing passive absorption on the side walls to minimise reflections into the main test area. Alternatively active absorption, in the form of additional mechanical wave-makers, may also be provided e.g. the FloWave circular wave basin (FlowWave, 2016) however this is an expensive solution. Another approach is to utilise intentional reflections from the side walls into the main test area, e.g. Dalrymple (1989), Gilbert and Huntington (1991) and Molin (1994) which increase the area in a tank which exhibits a homogeneous wave field. These methods have been validated experimentally by Mansard and Miles (1994) and Roux de Reilhac et. al (2008). While these methods may be successful at generating a relatively homogeneous wave climate in an 'empty' wave basin (i.e. no test model installed) only passive or active absorption on all sides of the wave basin can deal with waves reflected and radiated from the model. The challenge is to achieve a balance between lateral absorption of wave energy and minimised diffraction due to the finite length of the wave-maker. If the wave paddles extend to the full width of the wave basin (e.g. wave paddle width=16m for the basin shown in Figure 1.1) there is no available 'width' for inclusion of 
absorption. On the other-hand, if the paddles do not extend for the full width of the basin, a transition panel (or wave guide) is required to prevent water sloshing around the sides of the wave paddles and affecting operation. The transition panels must eventually diverge to provide the full width of the wave basin and introduce absorption on the sides. As the transition panels diverge, waves diffract into the undisturbed area of the basin, spreading energy along the wave front. This may be accounted for by adjusting the wave amplitude generated at the wave-maker to allow for wave energy spread. In addition, where the wavelength is less than the total width of the wavemaker a more detrimental diffraction phenomenon may occur within the length of the basin known as the Fresnel interference regime (O'Boyle, 2013). This results in regions of constructive and destructive interference across the entire wave front, creating a non-homogeneous wave field throughout the basin.

This paper describes the development, testing and modelling of a new coastal wave basin built and originally commissioned at Queen's University Belfast in 2010. Following a fire in the building the facility was rebuilt in 2011. During the design, construction, refurbishment and final commissioning a range of important conclusions were reached which should be of benefit to anyone contemplating building or refining such a facility.

\subsection{Original wave basin set-up}

The wave basin is $18 \mathrm{~m}$ long and $16 \mathrm{~m}$ wide with an operating water depth of up to $0.65 \mathrm{~m}$. An adjustable floor facilitates testing at various depths and a range of bed profiles. The original setup of the tank geometry and bathymetry is shown in Figure 1.1. Wave generation is provided by 24 no. $500 \mathrm{~mm}$ wide piston type, sector carrier wave paddles supplied by Edinburgh Designs Ltd which have active absorption via a force feedback mechanism. Each element of the wave generator is independently driven and controlled enabling full three dimensional sea generation. From the outset the facility was equipped with absorbing beaches on three sides to minimise unwanted reflections particularly in the transverse direction. This was achieved by limiting the wave generator to a total 
width of $12 \mathrm{~m}$ thus leaving $2 \mathrm{~m}$ on both sides for the longitudinal beaches. When first commissioned in 2010 the back beaches consisted of folded geotextile material (see Figure 2.4 A). The side beaches comprised concrete slabs which formed a steep impervious slope of 1:2 at its steepest point with its top edge at mean water level and shoaling further back in the tank (see Figure 2.4B). Straight panels provided the transition from the outer edge of the wave generator to the side beaches.

Design guidance was taken from previous experience with a 4.5 metre wide tank, knowledge and expertise provided by Edinburgh Design Ltd. (the wave-maker manufacturer) (E Designs, 2014) and publications such as Cruz (2008) and Hughes (1993).

\section{Performance enhancement}

While commissioning the completed basin in 2010 the performance was assessed in detail revealing that the characteristics fell short of the original expectations (O'Boyle et al., 2011) which lead to a review of the design. Due to the water depth within the basin $(\max 0.65 \mathrm{~m})$ evanescent waves are negligible by $2 \mathrm{~m}$ beyond the wave-maker (Dean and Dalrymple, 1991) and therefore do not contribute to the observed variations. Contamination of the wave field by spurious modes is also a common occurrence in directional wave basins due to mechanical generation of waves (see Schäffer, 1998 \& Spinneken and Swan, 2012). For this wave basin set-up spurious modes do not exist for wave frequencies less than $1.4 \mathrm{~Hz}$ and directions less than $40^{\circ}$ between the line perpendicular to the wavemaker and the propagation direction, therefore these too were disregarded as the source. The main cause of the variable wave climate was identified as a combination of poor absorption on the sides and back wall of the basin and the occurrence of a Fresnel type diffraction pattern due to linearly diverging transition panels between the wave-maker and the side beaches (O'Boyle, 2013).

In late 2010 a programme to modify the basin to improve performance was implemented. This section describes the methodology employed and details how the implemented solution ultimately showed major improvements compared to the original layout. This was achieved via a combination 

laboratory tests to improve beach performance and reflection characteristics.

\subsection{Transition panel design}

A numerical modelling investigation was carried out to assess whether the effects of the Fressnel diffraction regime could be minimised through simple alterations to the basin layout. Numerical modelling of the wave basin was carried out using a Boussinesq Wave model, MIKE 21 BW, to assess variations in transition panel shape. An optimal transition panel shape was selected, where divergence between the paddles and edges of the basin was provided whilst maintaining a relatively homogeneous wave field. Each of the considered transition panels were evaluated based on the wave field within a small and larger operational area defined in Figure 1.1.

\subsubsection{Numerical model set-up}

Boussinesq models are phase resolving wave propagation models based on a set of non-linear partial differential equations known as the Boussinesq Equations. The classic equations approximate wave propagation by eliminating the vertical component of velocity while still accounting for the vertical flow structure, assuming an incompressible fluid and irrotational flow. As a result of this depth averaging, the use of the classic equations is limited to water depths less than 0.25 times the deep water wavelength. Boussinesq models are usually mathematically enhanced versions of the classic equations which are modified to include, among other things, the effects of greater water depths. One such model is the Boussinesq Wave Model (BW) provided as part of the MIKE 21 suite of software developed by the DHI Water and Environment (DHI, 2008). This model is based on enhanced Boussinesq equations (Madsen and Sorensen, 1992). The formulation allows modelling into deeper water with a max depth limit of 0.5 times deep-water wavelength. The MIKE 21 BW modelling tool was designed for full scale applications but has been previously used at laboratory scale O'Boyle et al. (2011) and validated with experimental data. This model set-up was modified to assess how the wave basin performance could be improved. 
The model domain was a 304 by 376 square grid with a spatial resolution of $0.05 \mathrm{~m}$. Bathymetric data was implemented based on wave basin specifications for the re-construction of the wave basin which was different from the original bathymetry in Figure 1.1. The modelled bathymetry consisted of a constant bed level of $0.5 \mathrm{~m}$ immediately in front of the paddles extending for $4 \mathrm{~m}$, followed by a short steep section at 1:16 for $2.4 \mathrm{~m}$. The remainder of the basin was at a constant slope of 1:48 to the beach at the back. This bathymetric profile was eventually realised in the finished wave basin, as shown in Figure 4.1. Water depths of up to $0.65 \mathrm{~m}$ are possible. Given the maximum modelled water depth of $0.5 \mathrm{~m}$ the cut-off frequency for enhanced Boussinesq modelling is $1.25 \mathrm{~Hz}$. Waves within this limit were generated at the position of the wave paddles using an internal generation line. This generates waves propagating in both the forward (into the main model domain) and backward directions. The internal generation line was backed by a 50 cell sponge layer to absorb waves leaving the model domain in this direction. This sponge layer also allowed simulation of the force feedback feature of the paddles by absorbing all energy propagating from the model domain towards the paddles (note that the exact absorption characteristics of the paddles were not implemented). In order to assess the effect of varying the transition panel shape independently, fully absorbing sponge layers were also included along the back beach and on both sides of the basin (i.e. isolating the effect of beach absorption). In reality these are gravel beaches and will not behave as perfect wave absorbers.

\subsubsection{Data extraction and analysis}

In this study spatial homogeneity is of key interest, thus the performance of transition panels are assessed based on the standard deviation of the wave disturbance parameter. Wave disturbance is the ratio of the significant wave height observed in a particular cell in the model domain to the significant wave height requested at the centre of the wave-maker. In this case the waves simulated in the Boussinesq model are monochromatic, i.e. all the energy is confined to a single frequency. The significant wave height $\left(\mathrm{H}_{\mathrm{mo}}\right)$ is calculated based on the variance of the surface elevation at each 
point in the model domain. Where a sea state is comprised of a number of wave frequencies the amplitude of individual frequency components is calculated separately, as otherwise the lack of homogeneity may be masked (O'Boyle et. al. 2011). The standard deviation is determined for two operation areas as shown Figure 1.1. The large operation area gives a good indication of the performance of the larger part of the wave basin. The smaller operation area in the centre of the basin avoids skewing of the statistics due to measurements in very close proximity to the transition panels and beaches, particularly in angled seas.

\subsubsection{Discussion of results}

A number of straight, linearly sloped and curved transition panel arrangements were tested numerically in a range of monochromatic wave periods $(0.89 \mathrm{~s}, 1 \mathrm{~s} 1.14 \mathrm{~s}$ and $1.33 \mathrm{~s})$ and incident wave angles $\left(0^{\circ}, 15^{\circ}\right.$ and $\left.25^{\circ}\right)$ and a polychromatic wave packet (see Appendix A, Table A.1). The different sloped and curved transition panels with the original configuration given for comparison are shown in Figure 2.1.

The following is a summary of the key findings of the investigation. In the interest of brevity only results from the $1 \mathrm{~s}$ monochromatic wave simulations are presented here. The full investigation is presented in O'Boyle (2013).

\subsubsection{No transition panel}

One simulation was carried out for a configuration with no transition panel. In this case the absorption layer begins immediately at the wave paddles (see Figure 2.1 F1) and continues along the sides and the back to the basin. This configuration caused an increase in the diffraction effect on the wave climate compared to the original configuration. The standard deviation of the wave disturbance values in the large operation area increased by over $50 \%$ in normally incident monochromatic waves of $1 \mathrm{~s}$ wave period compared to the original configuration. 


\subsubsection{Straight transition panels}

197 Simulations were also carried out for straight, fully reflective transition panels of $0.5 \mathrm{~m}$ and $1 \mathrm{~m}$ length with absorption implemented immediately at the end of the panel (shown in Figure 2.1, F2 and F3 respectively). Similarly to the previous case, a solid reflective boundary runs perpendicular to the transition panel, between the panel and the edge of the basin. These configurations also show no improvement compared to the original configuration in both normal and oblique waves. However the results further support the argument of non-homogeneity occurring as a result of a Fresnel diffraction regime as they show an improvement in performance as the transition panel length increases from $0 \mathrm{~m}$ through $0.5 \mathrm{~m}$ and $1.0 \mathrm{~m}$, i.e. becoming more closely related to a straight side wall (as would be typical of a 2D wave tank). A further simulation was carried out containing a $1 \mathrm{~m}$ straight panel which, in contrast to F3 (Figure 2.1), is not backed by the reflective boundary (i.e. waves are allowed to propagate behind the panel and next to the wave paddles). This configuration shows an increase in standard deviation compared to a $1 \mathrm{~m}$ straight panel which is closed off.

\subsubsection{Linearly sloped transition panels}

Of the sloped transition panels investigated (S1, S2, S3 and S4 in Figure 2.1) only S2 and S3 showed an improvement compared to the original layout. This improvement was confined to the obliquely incident wave conditions, benefiting from the shortened straight section when operating in oblique waves. In fact the performance in normally propagating waves was marginally poorer than the original configuration due to the overall reduction in the length of the panel (see Figure 2.2).

\subsubsection{Curved transition panels}

In all conditions tested, the curved transition panels (see $\mathrm{C} 1, \mathrm{C} 2, \mathrm{C} 3, \mathrm{C} 4$ and $\mathrm{C} 5$ in Figure 2.1) perform significantly better than both the sloped transition panels and the original configuration (as shown in

Figure 2.2). The standard deviation in wave climate for normally propagating waves reduces for increasing panel length, similar to observations of the straight and linearly sloping transition panels. 
increased. However all curved panels offer a significantly more homogenous wave field compared to

222

223

224

225

226

227

228

230

231

232

233

234

235

236 the original configuration even in oblique waves. Results show the longer, more elongated, panel (C3) to perform best in normally propagating waves, differing only slightly from the results for a full side wall running the entire length of the basin (as in a 2D wave tank, but for non-oblique waves only). The shorter form of $\mathrm{C} 2$ works best for obliquely incident waves. The form $\mathrm{C} 5$, which has a profile described by $y=x^{3.5}$, seems to provide the best overall performance in directional waves without a large compromise in wave performance for normally propagating waves.

\subsubsection{Summary}

The form C5 has emerged as the best solution to improve the homogeneity of the wave field for the particular geometry of this Wave Basin. However the findings and methodology presented here are not thought to be limited to this study, but would certainly be beneficial to the design and enhancement of many other 3D wave basins. Figure $\mathbf{2 . 3}$ contains contour plots of wave disturbance values calculated from the MIKE $21 \mathrm{BW}$ model simulations for $\mathrm{C} 5$ and the original configuration in both normally and obliquely incident monochromatic waves of $1 \mathrm{~s}$ wave period. Note the increased homogeneity in the wave field due to the introduction of the curved side panels in the lower subplots, particularly for waves at 0 degrees. It is also possible to observe diffraction of wave energy into the quiescent area of the basin, particularly for oblique waves, and the numerical absorption of wave energy on the model boundaries and behind the wave-maker.

\subsection{Wave energy absorption}

Wave absorbers may be distinguished into two categories. Passive absorbers, which physically damp incident wave motion; and active absorbers, which are mechanical devices, similar to a wave-maker, that move in response to the incoming wave measured either using a wave gauge or force transducer. This type of wave absorption is often provided at the wave-maker to avoid re-reflection and subsequent build-up of the wave condition with time. The Edinburgh Designs wave paddles 

2009b).

247 A survey of passive wave absorbers by Oullet \& Datta (1986) presents the findings of a questionnaire

248 sent to 162 hydraulics and ship model tank laboratories requesting details of the absorption

249 techniques used (including material, slope, length, water depth, wave conditions) and efficiency,

250 where it could be estimated. Of 48 replies the survey found that absorbers of a parabolic profile were most efficient and that performance may be improved by the addition of roughness and porosity.

An overview of general design considerations of wave basin absorption is outlined below. This is followed by details of how an appropriate beach design for the Portaferry Wave Basin has been selected.

\subsubsection{Porous beach design}

257 General considerations for the design of laboratory absorption techniques are:

- Active absorbers may be effective if measurement of the incoming wave amplitude and phase is accurately taken and utilised, however the cost of such installations rules them out for many applications (Hughes, 1993).

- Gently sloping porous absorbers (less than 1 in 10) are most common; however require a lot of space within the wave basin/flume (Oullet \& Datta, 1986).

- According to Hughes (1993) constant sloping beaches made of gravel or stones cannot be easily moved and so become impractical in situations where the layout of the basin is frequently changed. Modular beach units can be moved more easily and are therefore preferred in this context. However in larger facilities where material can be moved with cranes and mini diggers gravel beaches also give certain flexibility. 
- Most wave absorbers work well for a specific design frequency, wave height and water level; it is more difficult to ensure reasonable absorption over a broad spectrum of wave conditions and multiple water depths (Hughes, 1993).

- The working area in a basin may be maximised in basins designed for deep water applications by truncating the sloping face before reaching the bed level and instead adopting partial slope and vertical step, similar to Figure 2.4 F (Tiedeman et al., 2012).

- Deterioration of materials of the absorber (e.g. horse hair in vertical mesh screens or re-grading of sloped granular material over time) can give rise to decreased efficiency (Maguire, 2011).

- Where more precise knowledge of the incident wave spectra and directionality is required (e.g. wave energy converter (WEC) device optimisation and array modelling), absorption should be provided on all sides of the basin but care should be taken not to limit the size of the test area so that for example the testing of large WEC arrays becomes impractical (O'Boyle, 2013).

- For experiments involving highly reflective or radiating models, tests may be run in short bursts so that data is captured before reflections have contaminated the experiment ( $O^{\prime}$ Boyle, 2013). However this requires the instantaneous response of the structure to be tested to the incoming waves.

\subsubsection{Selecting a suitable absorption technique for Portaferry Wave Basin}

The following describes an experimental investigation of porous beaches to improve the absorption characteristics of the original beach in Portaferry Wave Basin within its operating range $(0.5 \mathrm{~Hz}-$ basin (Figure 2.4 A) with steep impervious slopes at maximum steepness of 1:2 along each side

(Figure2.4 B). Based on a review of absorption techniques (Hughes, 1993; O'Boyle, 2013) it was proposed to replace the steep impermeable side slopes with a porous material and that absorption at the rear may also be improved. Experimental testing of different porous beach arrangements was carried out in the 2D wave tank in the Hydraulics Laboratory at Queen's University as the Portaferry Wave Basin was decommissioned at the time. The investigation included different gravel sizes, water 
levels, beach types and beach slopes as shown in Figure 2.4. Despite the reported efficiency of parabolic beaches (Oullet \& Datta, 1986) calculation of the optimum profile (Svedson, 1985) revealed that the length required for the absorber would not allow a sufficient test area within the basin and so this was not tested experimentally. Details of the experimental set-up and testing procedures may be found in Maguire (2011) and Iventic (2011). The main findings are outlined as follows where reflection coefficient is defined as:

$$
\text { Reflection Coef ficient, } K R=\frac{\text { amplitude of the reflected wave }}{\text { amplitude of the incident wave }}
$$

\subsubsection{Beach slope}

A porous gabion type, vertical face wave absorber (as shown in Figure 2.4 C) was tested and shown to behave most poorly of all the variations with reflection coefficient values of between 0.25 and 0.65 for the range of wave conditions tested in Iventic (2011). Plane sloping beaches (as shown in

Figure 2.4 D) at gradients of 1:4, 1:6, 1:8 and 1:12 were also tested in both monochromatic and irregular waves. The 1:8 and 1:12 slopes performed best within the operating conditions of Portaferry Wave Basin with measured values of reflection coefficient not exceeding 0.18 and regularly falling below 0.1 for an absorber length of $1.5 \mathrm{~m}$. The $1: 8$ slope was chosen as the most practical solution, achieving acceptable levels of wave absorption with minimal space required when compared to the 1:12 slope.

\subsubsection{Flat ' $v$ ' inclined bed}

Additional tests were carried out to investigate the effect of having a flat versus an inclined base to the beach (Maguire, 2011) such as shown in Figure 2.4 D and E. It is found that overall beaches with a flat base perform best, reducing wave reflection by up to $50 \%$ when compared to the same beach with an inclined bed. The greatest differences are observed for beaches with the steepest slopes. 


\subsubsection{Gravel size}

318 Two different gravel sizes were tested (i.e. $22-40 \mathrm{~mm}$ and $\approx 14 \mathrm{~mm}$ quarried gravel from quarzite/plum slate) to determine the most suitable size for absorption of wave energy in the required operating range. The larger gravel was found to perform best due to having a higher porosity than the smaller gravel. In addition, it was found that the beach, when formed of the smaller gravel, would regularly reshape and become steeper due to the action of wave breaking, which in turn increased the reflection from the beach (Iventic, 2011).

Based on the findings above gravel beaches composed of the larger stone $(22-40 \mathrm{~mm})$ were selected as the best beach design for Portaferry Wave Basin. The bed beneath the beach at both the sides and back of the basin was kept flat. A slope of 1:8 was selected for the top profile of the back beach. Due to space restrictions the top profile of the side slope was limited to 1:5, however the effective steepness is shallower as waves typically penetrate the side beaches at oblique angles to the slope.

\section{Performance assessment}

Following implementation of the modifications described above, the performance of the wave basin was assessed though wave climate mapping (similar to that carried out by O'Boyle et al. (2011)) and reflection analysis on the new absorbing beach. Details of the assessment and results are presented below.

\subsection{Wave field variation}

\subsubsection{Experimental set-up}

The wave climate was mapped using a bespoke polychromatic wave packet. A polychromatic wave packet may be defined as a sea state containing a discrete number of frequency components with a range of amplitudes so that the total energy in the sea state is similar to that in a standard wave spectrum, while the amplitude of each frequency component is greater than would be possible for standard irregular waves (O'Boyle, 2013). The wave packet used here contains a total of 7 discrete 
frequency components generated simultaneously at the wave paddles. The polychromatic wave packet allows assessment of the homogeneity of the wave field in a large area and a range of operating frequencies without the need to sample each frequency component individually thus minimising tank time (O'Boyle, 2013). An added advantage over using standard irregular wave generation is that the amplitude of each component (and thus the associated interferences) is larger due to the reduced total number of frequency components compared to a wave spectrum of increased frequency resolution. This allows variations in individual components to be identified outside experimental error. Table 3.1 gives the properties of each component.

The surface elevation is sampled using a total of 29 standard twin wire wave probes, spaced $100 \mathrm{~mm}$ apart, on a beam spanning laterally within the basin. The beam is in turn mounted on the overhead gantry. The polychromatic wave condition is run continuously and data is recorded for a repeat time of $32 \mathrm{~s}$ at a single location before the gantry is moved by $100 \mathrm{~mm}$ and the process is repeated to complete a run of $5 \mathrm{~m}$ requiring approximately 1 hour of test time. A delay of at least 10 s is allowed between ceasing gantry movement and starting data acquisition which is deemed sufficient to allow any disturbances caused moving the gantry to dissipate. The probes are then moved laterally on the gantry to begin another run in the same way. Just two runs are required to map a sufficiently large area in one half of the wave basin. Previous studies have shown that the diffraction pattern in the basin is relatively symmetrical, neglecting effects of variations in bathymetry. The total mapped area for this study is $5.45 \mathrm{~m}$ laterally and $5 \mathrm{~m}$ in the longitudinal direction. The position of the mapped area within the wave basin is shown in Figure 4.1.

\subsubsection{Results}

The surface elevation data at each point in the mapped region is first corrected to still water level, followed by a Fast Fourier Transform (FFT) analysis on the wave trace to obtain the amplitude of each of the 7 frequency component at each location in the region. These values are then normalised based on the amplitude requested from the wave-maker (Table 3.1) as given by: 
This value is often referred to as bias index. As can be seen from above having a value of zero would mean a perfect match, whereas a value greater than zero corresponds to a wave amplitude greater than observed, with a value of 1 being twice the requested wave amplitude.

Some erroneous values due to acquisition malfunction (out of range of the wave probe amplifier) were removed in post processing. Contour plots comparing the variation in measured amplitude of each frequency component of the polychromatic wave packet before and after modification to the wave basin layout are created based on the bias index. Figure 3.1 shows the variation in measured amplitude for 3 components of the polychromatic wave packet, the $0.625 \mathrm{~Hz}, 0.875 \mathrm{~Hz}$ and $1.125 \mathrm{~Hz}$, before and after the implemented modifications. As can be seen there is significantly less variation in the new wave basin compared to the original configuration.

\subsubsection{Statistical comparison of wave basin configurations}

Assuming a distribution of the measured wave amplitude either side of the requested value, it is also possible to look at the frequency of occurrence comparable to a normal distribution of a measurement. Again this is ideally normalised by either the mean value of the observation or a requested value. The deviation of the mean value has been calculated in this instance for each wave component and the two wave basin configurations and the results are shown in Figure 3.2. These plots show the spread of measured wave amplitude is narrower for the revised configuration for all frequencies apart from $1.25 \mathrm{~Hz}$ and $1.375 \mathrm{~Hz}$ which show a similar spread to the original configuration. As a result, the number of measurement points in this wave field where the mean wave amplitude is matched (value of 1) has increased, demonstrating that the spatial variation of wave amplitude in the revised wave basin has been greatly reduced. Overall the wave climate in the wave basin is substantially more homogeneous due to the improvements carried out. 


\subsection{Absorption of wave energy by the beach}

The absorption of the new porous beach was assessed by measuring the reflection co-efficient using the Mansard and Funke (1980), 3 probe method. The reflection coefficient was calculated for 7 wave frequencies (in the range $0.73 \mathrm{~Hz}-1.25 \mathrm{~Hz}$ ) and 4 wave amplitudes $(5 \mathrm{~mm}, 15 \mathrm{~mm}, 25 \mathrm{~mm}$ and $35 \mathrm{~mm}$ ). The wave probe spacing for each frequency component was determined based on recommendations outlined in Mansard and Funke (1980). A linear array of 7 wave probes allows the reflection coefficient at multiple wave frequencies to be determined without the need to change the probe set-up between individual runs. In a 3D basin, multidirectional phase locking of waves may impact the calculation of the reflection coefficient using the three probe method, as each probe is positioned in a different wave climate. Multi-directional effects were accounted for by assessing the reflection coefficient using a number of different probe sets, which are slightly spatially separated. different probe sets allows the confidence limits of results to be determined (Schjø|l Brede, 2013).

Figure 3.3 shows the reflection coefficient (defined by eqn. 3.1) results with individual subplots for each wave amplitude showing the mean value and individual results obtained from different probe sets. The mean reflection coefficient for all wave conditions tested was 0.08 and is also shown as a dotted red line (Schjøll Brede (2013)). This is equivalent to less than $1 \%$ reflection of wave energy. In general, the reflection coefficient falls between 0.05 and 0.15 for all amplitudes, frequencies and water depths tested. Greater variation was noted in the calculated reflection coefficient as the wave frequency increased, agreeing with results of wave climate variability presented in Section 3.1. The greatest reflection coefficient (0.24) was recorded for the highest frequency component $(1.25 \mathrm{~Hz})$, however the percentage energy absorption is still greater than $94 \%$. Additional work by Lamont-

412 Kane et al. (2013) has shown that the temporal variation of the wave field in the improved Portaferry Wave Basin is generally less than $1 \mathrm{~mm}$ wave amplitude in both monochromatic and irregular waves. 


\section{Description of improved wave basin}

416 This optimisation study has resulted in a wave basin which is significantly improved in terms of wave

417 climate variability and energy absorption. The current layout of the wave basin and bathymetry is shown in Figure 4.1. Parabolic transition panels are provided at each side of the wave paddles to prevent 'sloshing' of waves behind the paddles. These panels gradually diverge to provide the full operating width of the basin. The shape of the transition panels has been optimised, using the MIKE $21 \mathrm{BW}$ model, to reduce variability in the wave climate due to diffraction effects. An absorbing gravel beach at the back of the basin (down wave) is provided to minimise longitudinal reflection of wave energy. The down wave beach has a 1:8 slope extending $2 \mathrm{~m}$ towards the back wall of the basin and is topped by an additional geotextile mattress to further aid absorption of higher frequency wave components. Additional gravel beaches along both sides of the basin provide absorption of directional and transverse waves. The side beaches run in line with the extent of the wave paddles and have an initial vertical step of $0.35 \mathrm{~m}$ at the deepest section, followed by a 1:5 slope extending $1.5 \mathrm{~m}$ towards the side walls.

Statistics show that the spatial variability and persistence of the wave climate have been greatly improved for frequencies below $1.25 \mathrm{~Hz}$ due to the modifications described here. The temporal variation in wave climate has been assessed and is generally less than $1 \mathrm{~mm}$ wave amplitude. Reflection analysis of the beach has shown the overall wave energy reflection is less than $1 \%$ for the frequency range typically used on this type of wave basin. The absorption properties deteriorate for higher frequencies and greater wave heights but do not fall above $6 \%$ energy reflection. It should be noted that for irregular waves the reflection coefficients may be different depending on the spectral shape and the characteristic wave height and wave length parameters chosen. 


\section{Conclusions}

The results presented here demonstrate the performance enhancement of a 3D coastal wave basin which was realised though simple changes to set-up and geometry based on high resolution wave climate mapping, and design optimisation based on numerical modelling. Although the study is specific to Portaferry Wave Basin, the processes leading to the variability and the enhancement methods adopted are likely to be applicable to many other wave basin design projects.

The following key conclusions should be beneficial to others seeking to design or improve a wave basin facility elsewhere.

- A combination of numerical model results with physical tests was invaluable in determining the causes of wave basin homogeneity and potential solutions to the problem. The ability of the model to replicate observations in the wave basin was assessed based on physical mapping of the original wave basin before being utilised efficiently to identify sources of interference and inform basin optimisation.

- This investigation has employed the use of a commercial numerical modelling tool (MIKE 21 BW) designed for full scale coastal applications. Comparison of physical results from the wave basin and the BW model results verifies the accurate representation of physical processes occurring at laboratory scale and validates the use of this model for small scale applications. (O'Boyle et. al., 2011)

- The phase resolving, Boussinesq model has been shown to be a valuable tool for the design of wave basin layout. The comparative flexibility of the numerical model allows the optimum wave basin design to be evaluated efficiently and with ease.

- A new method for efficient physical assessment of wave basin performance has been developed. This involved the use of a polychromatic wave condition which was generated continuously for the duration of the sampling, allowing the reflections and interactions to stabilise in the basin. Meanwhile the wave climate is mapped using a number of wave 
probes which traverse within the mapped area. This method has been demonstrated for normally incident waves but could be applied to oblique waves as well. Using a total of 29 wave probes an area of $2.8 \mathrm{~m} \times 5 \mathrm{~m}$ can be mapped in just over 1 hour.

- Lateral absorption introduced along the side walls of a 3D wave basin has significantly improved the homogeneity of the wave climate with little reduction to the total energy in the main working area. This should be accounted for when designing a wave basin as the performance of the beach increases with increased width.

- When providing lateral absorption, a transition is also required between the wave generator and the absorbing beaches. It was found that the profile of this transition panel can have significant effects on wave basin homogeneity and may induce a detrimental diffraction pattern when the wavelength was less than the total width of the wave-maker, which is most often the case. Numerical modelling was utilised effectively to optimise the shape of the transition panels for a particular wave basin, finding that curved panels perform significantly better than straight or linearly sloped designs.

\section{Acknowledgements}

477 Dr Louise O'Boyle was funded during her PhD through a grant from the Department of Employment

478 and Learning, Northern Ireland facilitated by the Institute for a Sustainable World, Queen's

479 University Belfast (http://www.qub.ac.uk/sites/isw/). The authors would like to acknowledge the provision of a software license by DHI Water \& Environment for Louise O'Boyle. The authors would particularly like to thank Cecilia Zambrano for her assistance in collecting wave tank data and completion of drawings and all others who participated in data acquisition including Patrick Maguire, contributed to the review process and have helped to improve the quality of this paper. 


\section{References}

486 Cruz, J., 2008. Ocean Wave Energy. Current Status and Future Perspectives., Springer.

DHI, 2008. MIKE 21 Boussinesq Wave Module - Scientific Documentation.

Dalrymple, R. A., 1989. Directional Wavemaker Theory with Sidewall Reflection. Journal of Hydraulic Research, Vol. 27, 1989, No. 1, pp. 23- 34.

Dean, R. G. and Dalrymple, R. A., 1991. Water Wave Mechanics for Engineers and Scientists. Advanced series on ocean engineering Vol.2, World Scientific Publishing.

E Designs, 2014. Company Website. [Accessed: 27 th Jan 2014] Available at: http://www.edesign.co.uk/.

FlowWave, 2016. Facility Website. [Accessed: 29th Feb 2016] Available at: http://www.flowavett.co.uk/.

Gilbert, G., and Huntington, S. W., 1991. A technique for generation of short crested waves in wave basin, Journal of Hydraulic Research, Vol. 29, No 6.

Hughes, S.A., 1993. Physical Models and Laboratory Techniques in Coastal Engineering. Advanced Series in Ocean Engineering - Vol.7, London: World Scientific Publishing Co. Pte. Ltd.

Iventic, D., 2011. Beach Design and Gravel Size Testing, Internal Report, Queen's University Belfast.

Maguire, P., 2011. Investigation of Wave Absorbing Beach, MEng Research Project, Queen's University Belfast.

Madsen, P. A. and Sorensen, O. R., 1992. A new form of the Boussinesq equations with improved linear dispersion characteristics. Part 2. A slowly-varying bathymetry. Coastal Engineering, Vol. 18, 183-204. Squares Method. Coastal Engineering, pp.154-172.

Mansard, E.P.D. and Miles, M.D., 1994. Experimental Validation of Directional Wave Maker Theory with Side Wall Reflections. Int. Journal of Offshore and Polar Engineering, Vol. 4. Cuve à Houle," DGA, Technical Report No. 1.04.32.0390.

O’Boyle, L. et al., 2011. Assessment of Wave Basin Homogeneity for Wave Energy Converter Array Studies. In 9th European Wave and Tidal Energy Conference. Southampton, UK.

O’Boyle, L., 2013. Wave Fields around Wave Energy Converter Arrays. PhD Thesis, Queen's University Belfast 
513 Oullet, Y. and Datta, I., 1986. A survey of wave absorbers. Hydraulic Research, 24(4), pp.265-280.

514 Roux de Reilhac, P., Bonnefoy, F. and Ferrant, P., 2008. Generation of Large Angle Bimodal Sea States Using

515 One-Side Segmented Wavemaker. Journal of Offshore mechanics and Arctic Engineering. Vol. 130

516 Schjøll Brede, H., 2013. Reflection Analysis of a new Gravel Beach Arrangement in Portaferry Wave Basin., 517 Internal Report, Queen's University Belfast.

518 Schäffer, H. A., 1998. Some Design Aspects of an Absorbing 3D Wavemaker. Proceedings of 26th Conference on 519 Coastal Engineering, Copenhagen, Denmark.

520 Spinneken, J. and Swan, C., 2009a. Second-order wave maker theory using force-feedback control. Part I: A new 521 theory for regular wave generation. Ocean Engineering, 36(8), pp.539-548.

522 Spinneken, J. and Swan, C., 2009b. Second-order wave maker theory using force-feedback control. Part II : An 523 experimental verification of regular wave generation. Ocean Engineering, 36(8), pp.549-555.

524 Spinneken, J. and Swan, C., 2012. The operation of a 3D wave basin in force control. Ocean Engineering. Vol. 55, $525 \quad$ pp.88-100.

526 Svedsen, I. A. (1985). Physical Modelling of Water Waves. In Physical Modelling in Coastal Engineering, R.A

527 Dalrymple, Ed., A.A. Balkeme, pages 13-47. Rotterdam, Netherlands.

528 Tiedeman, S. et al., 2012. A demountable wave absorber for wave flumes and basins. In 33rd Conference on Coastal Engineering. Santander, Spain. 


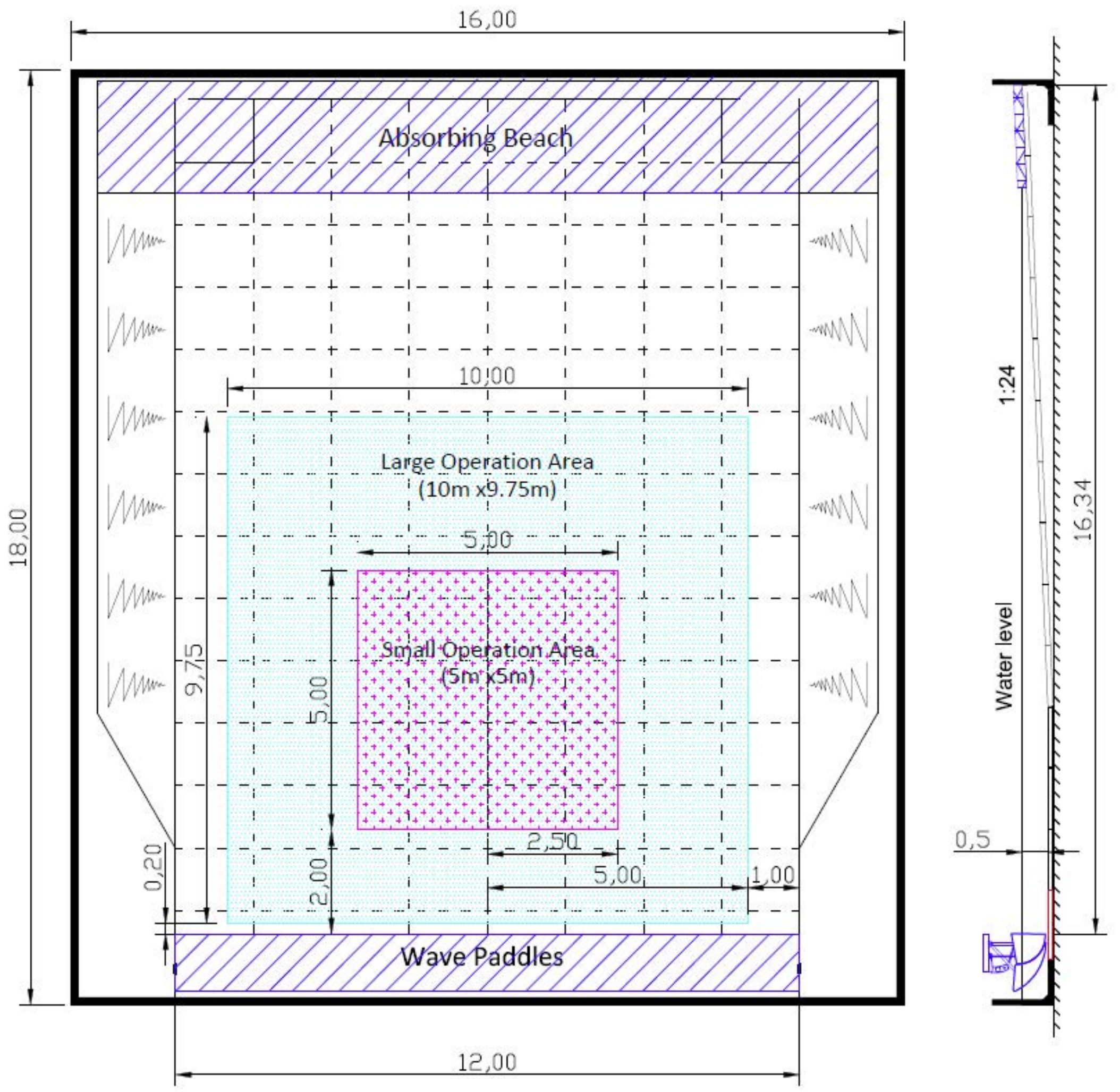



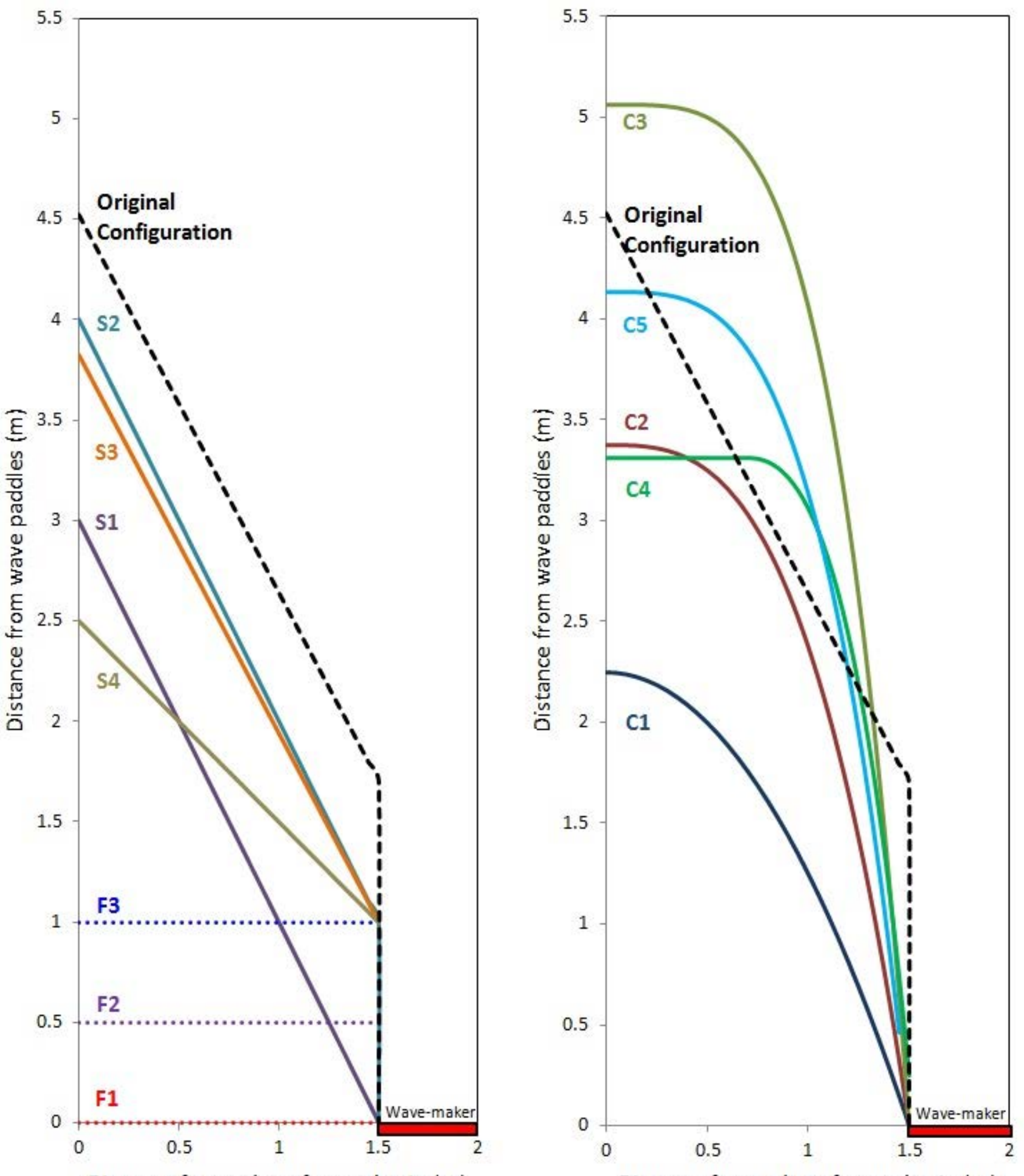

Distance from edge of wave basin ( $\mathrm{m}$ )

Distance from edge of wave basin ( $\mathrm{m})$ 


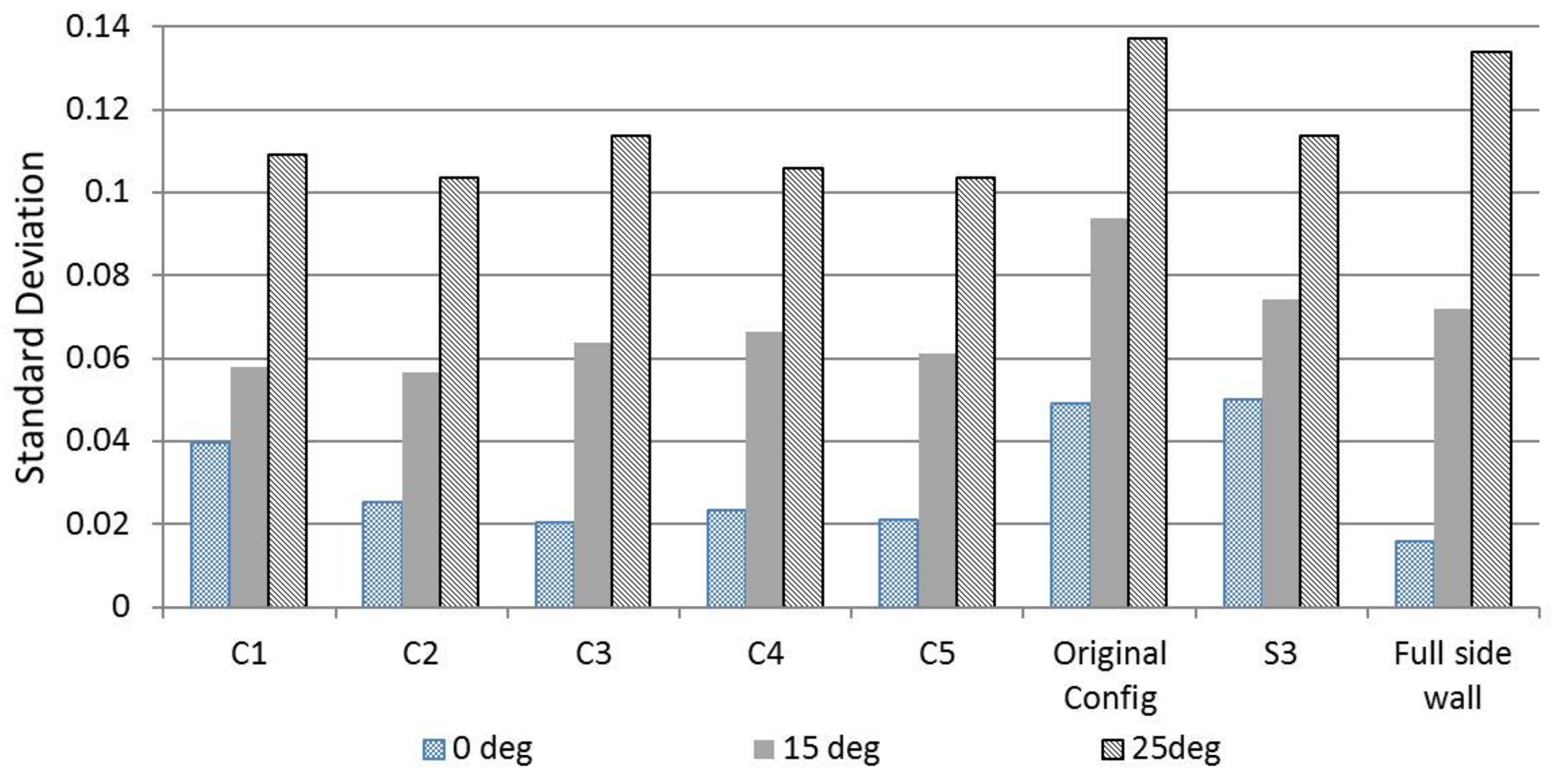



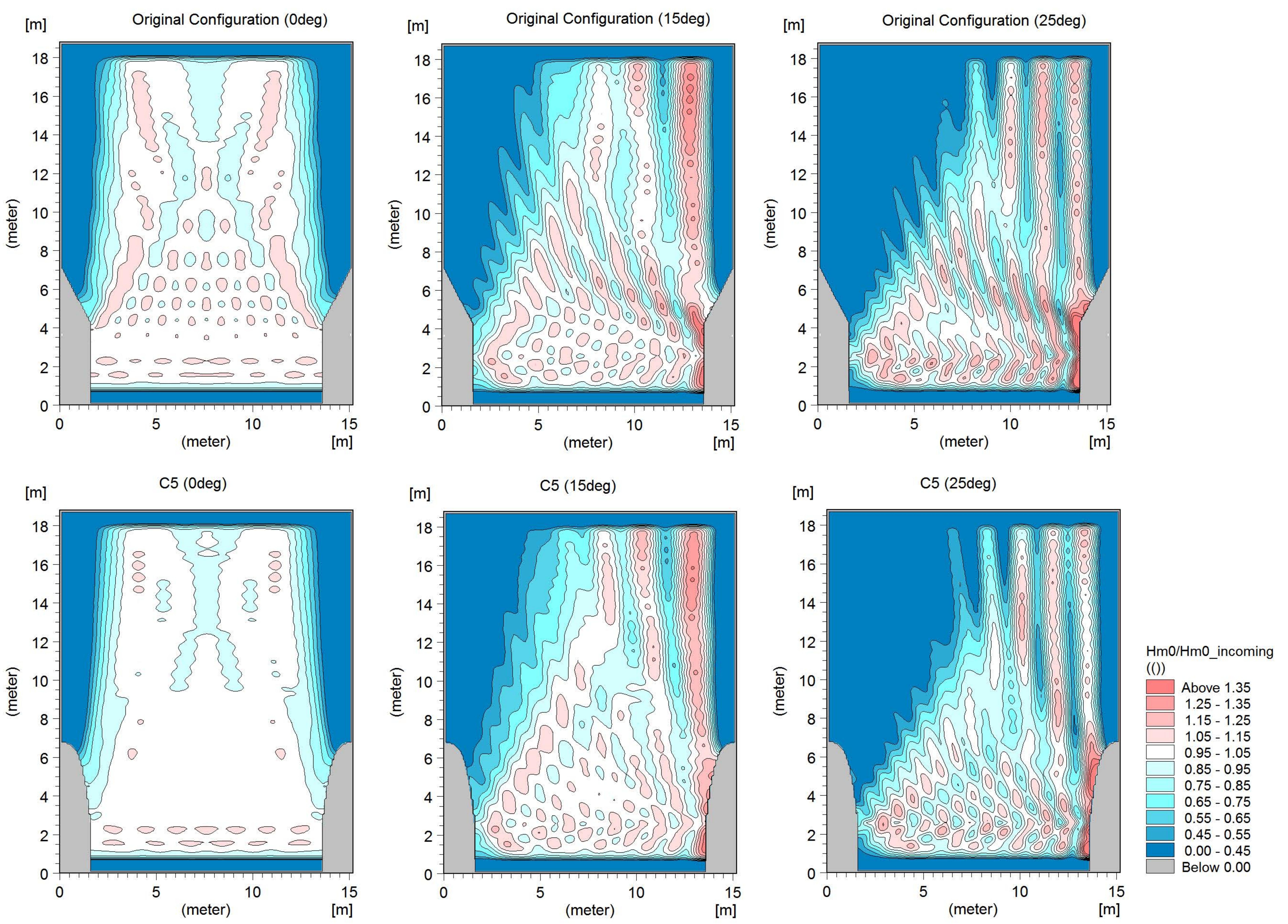


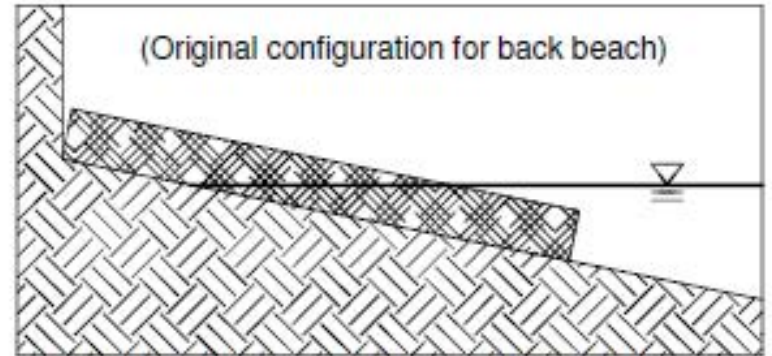

(A) Porous Inclined Beach Formed from Fabric Mattress

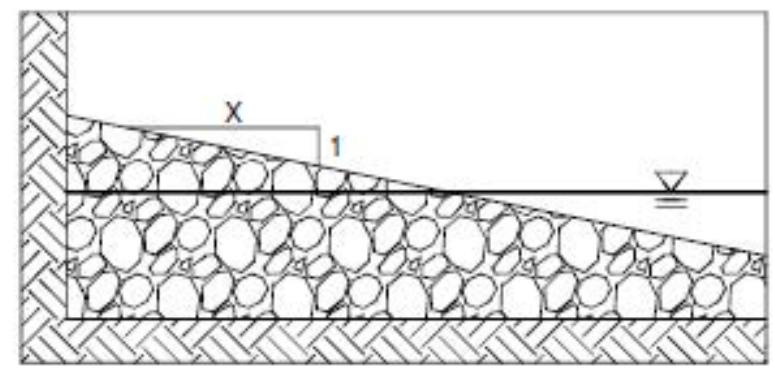

(D) Porous Plane Sloping Gravel Beach with Flat Bed (1:X Slope)

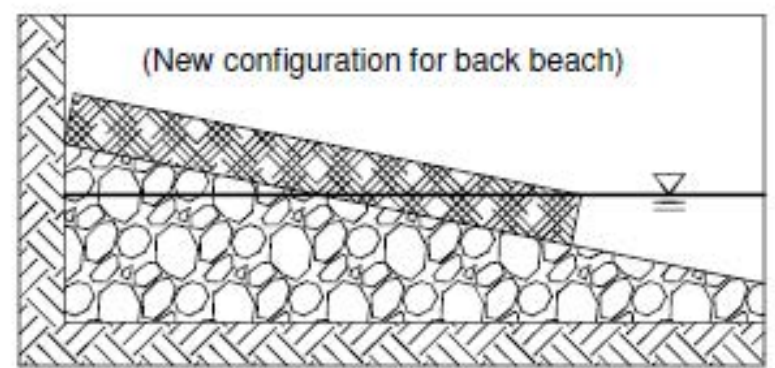

(G) Porous Plane Sloping Gravel Beach with Flat Bed and Additional Fabric Mattress

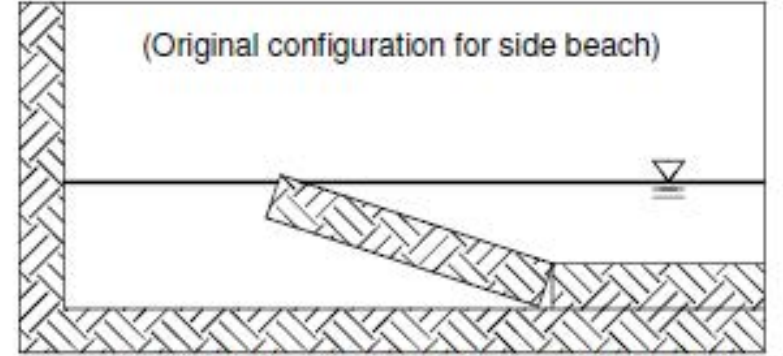

(B) Impermeable Plane Sloped Beach with Overflow Trough

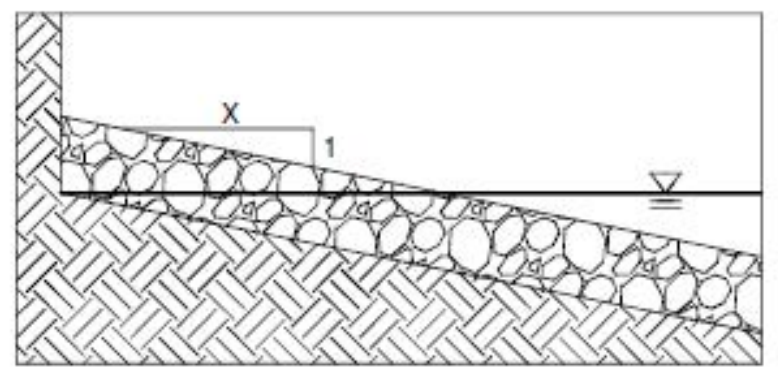

(E) Porous Plane Sloping Gravel Beach with Inclined Bed (1:X Slope)

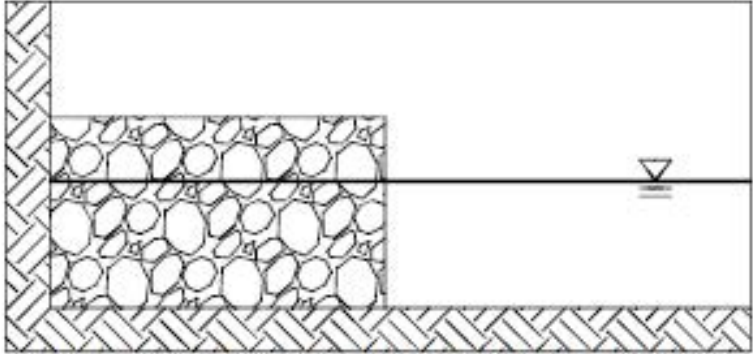

(C) Porous, Gabion Type Vertical Wave Absorber Formed from Gravel

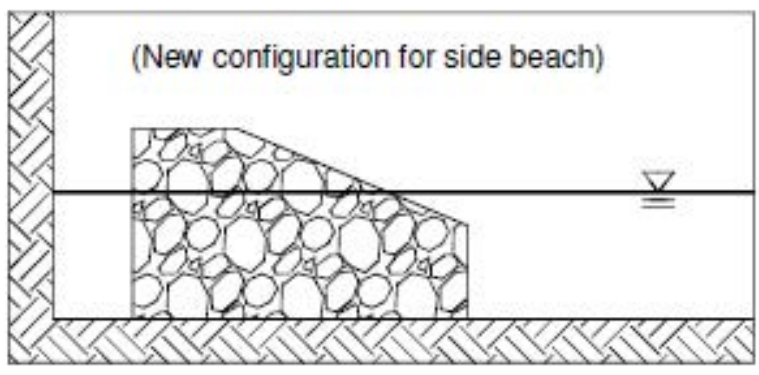

(F) Porous Plane Sloping Gravel Beach with Flat Bed and Vertical Step 
Original Configuration $0.625 \mathrm{~Hz}$

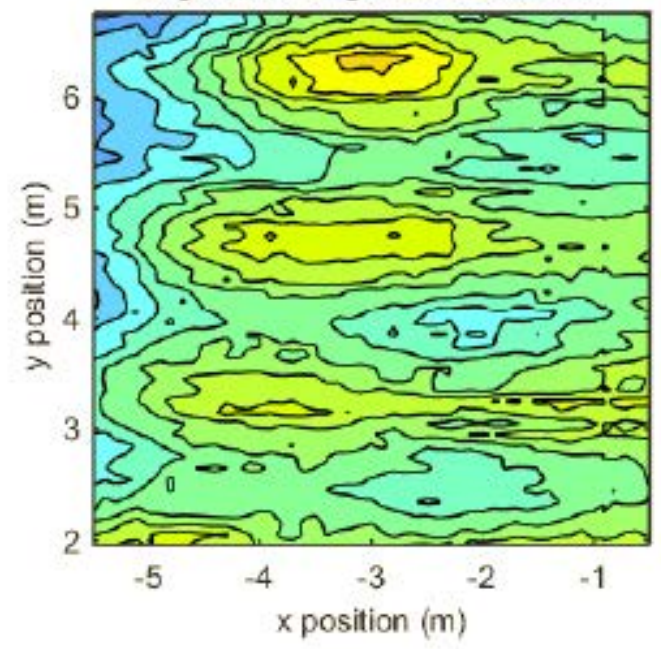

Original Configuration $0.875 \mathrm{~Hz}$

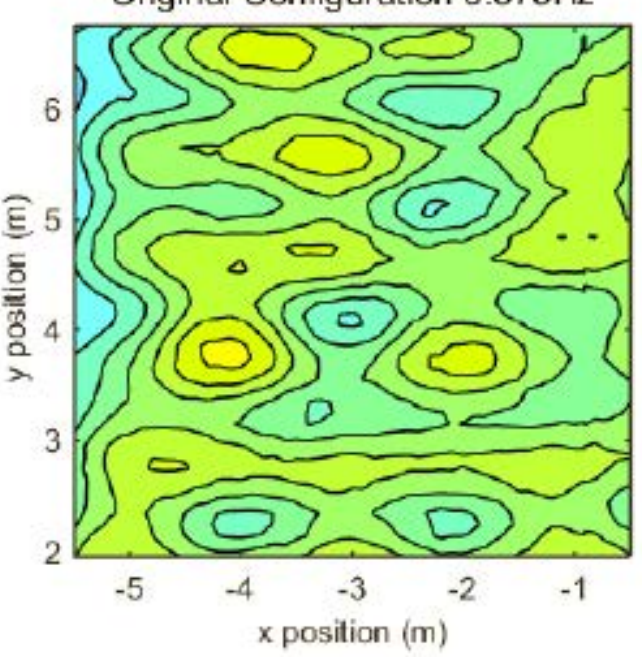

Original Configuration $1.125 \mathrm{~Hz}$

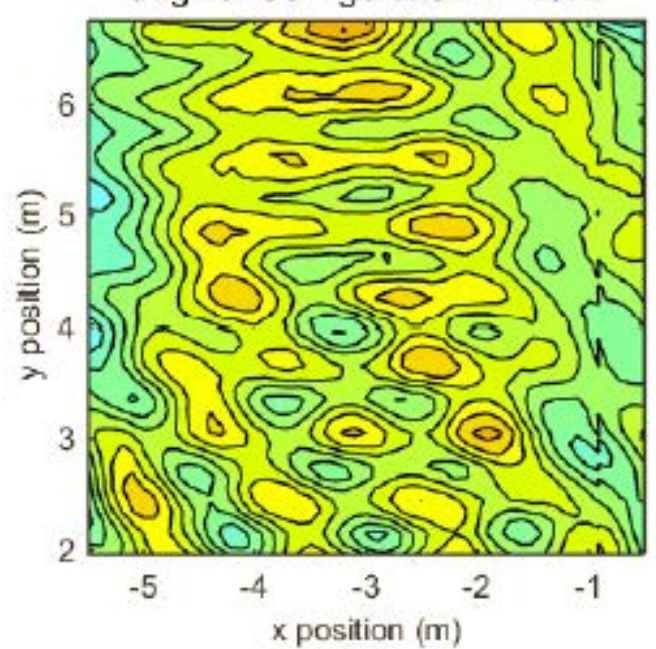

New curved side panels $0.625 \mathrm{~Hz}$

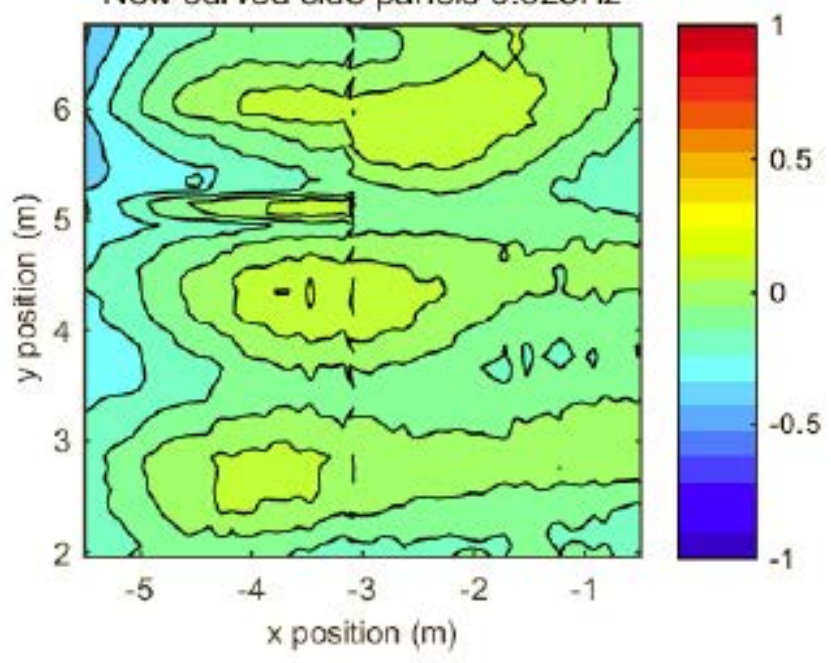

New curved side panels $0.875 \mathrm{~Hz}$

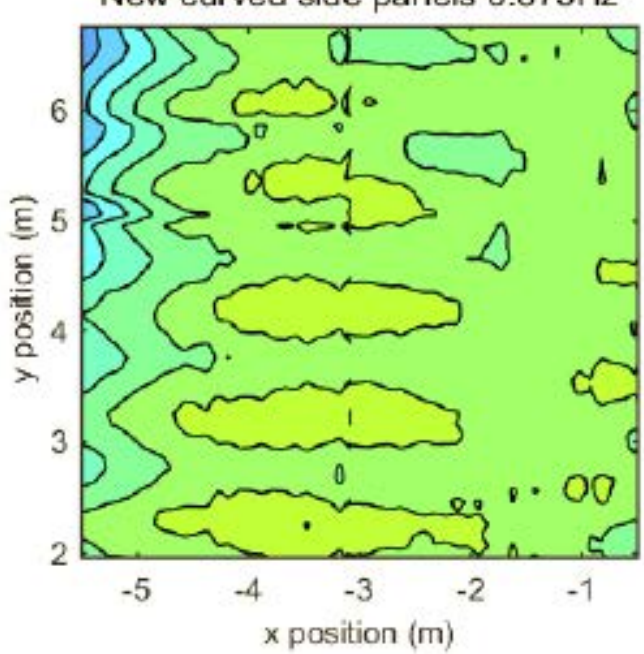

New curved side panels $1.125 \mathrm{~Hz}$

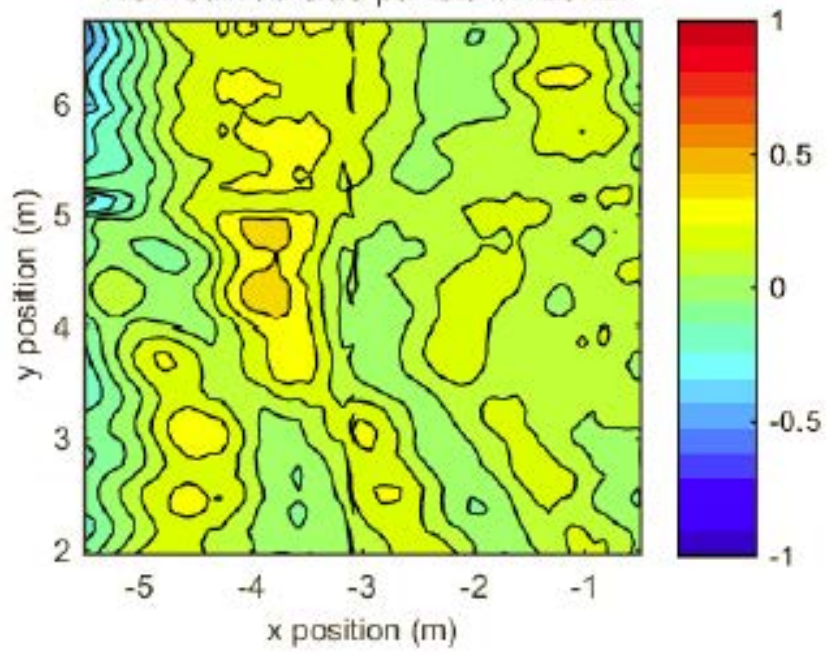


Freq component $0.625 \mathrm{~Hz}$

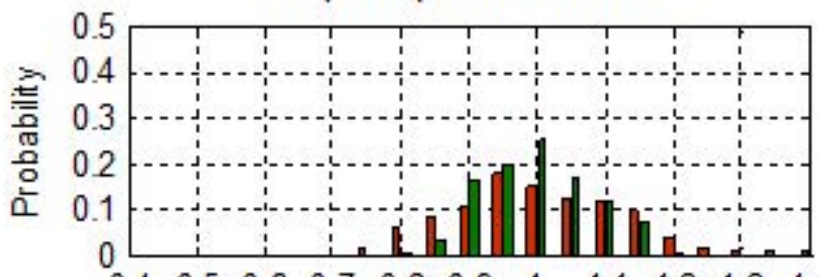

$\begin{array}{lllllllllll}0.4 & 0.5 & 0.6 & 0.7 & 0.8 & 0.9 & 1 & 1.1 & 1.2 & 1.3 & 1.4\end{array}$

Normaised Wave Amplitude

Freq component $0.875 \mathrm{~Hz}$

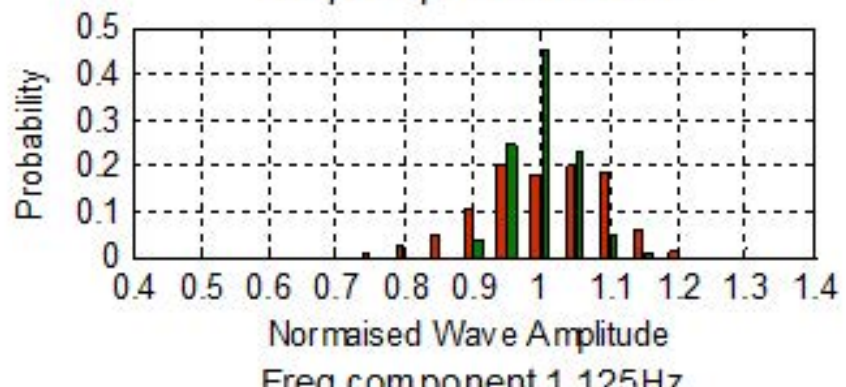

Freq com ponent $1.125 \mathrm{~Hz}$

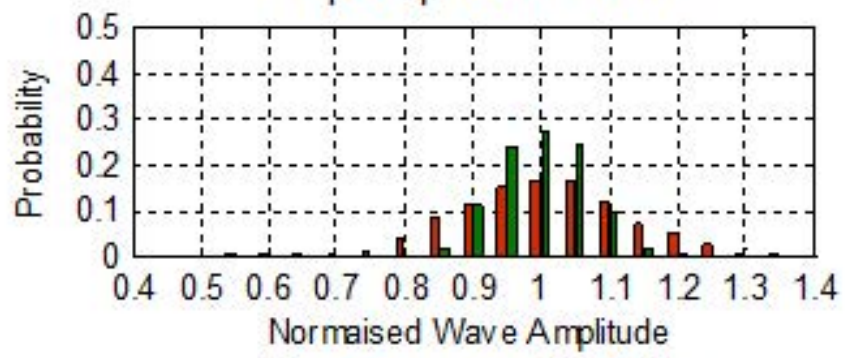

Freq com ponent $1.375 \mathrm{~Hz}$

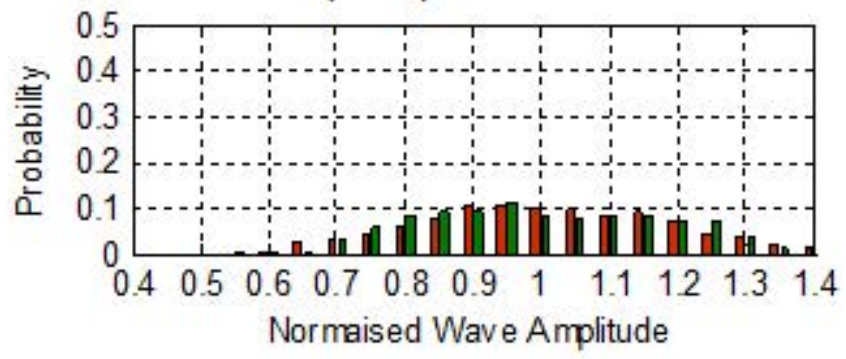

Freq com ponent $0.75 \mathrm{~Hz}$
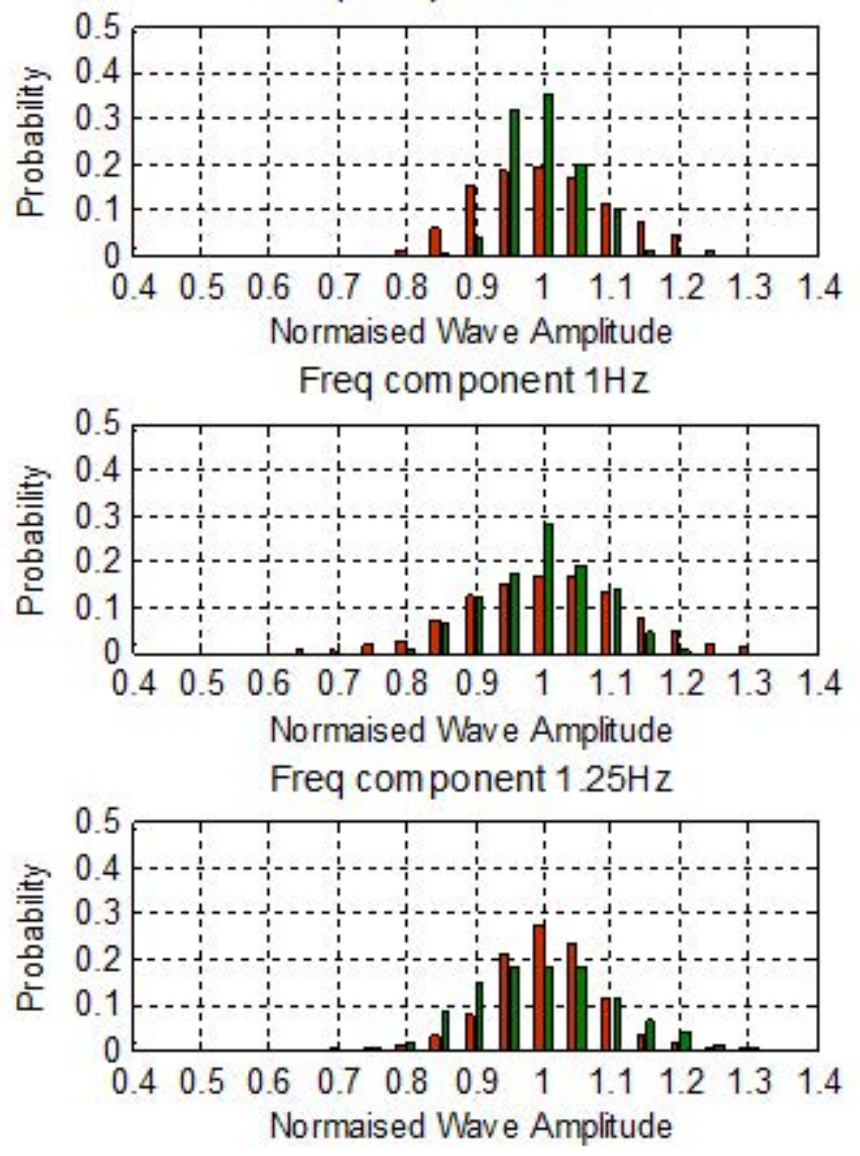

Old Configuration (2010) New Configuration(2012) 

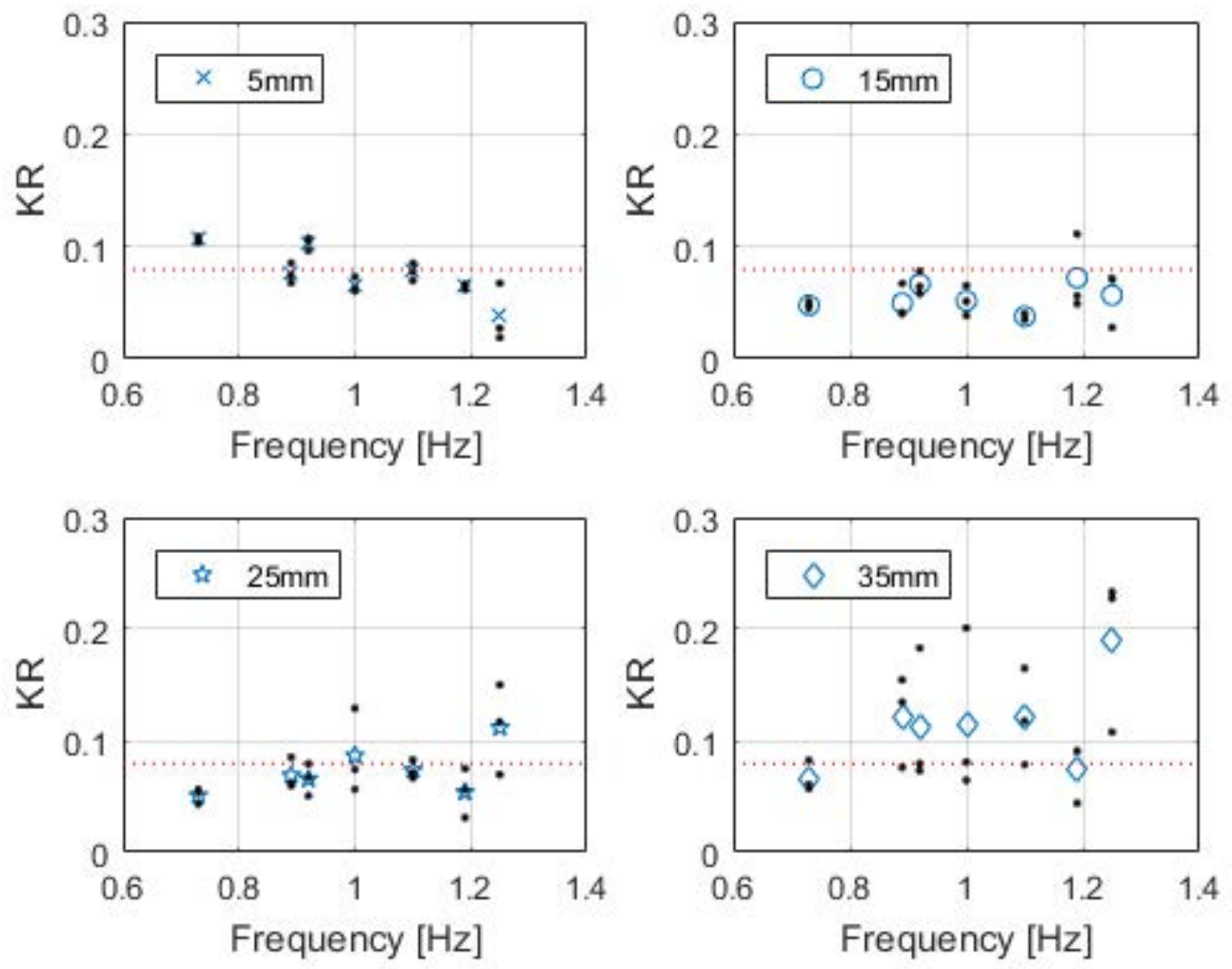


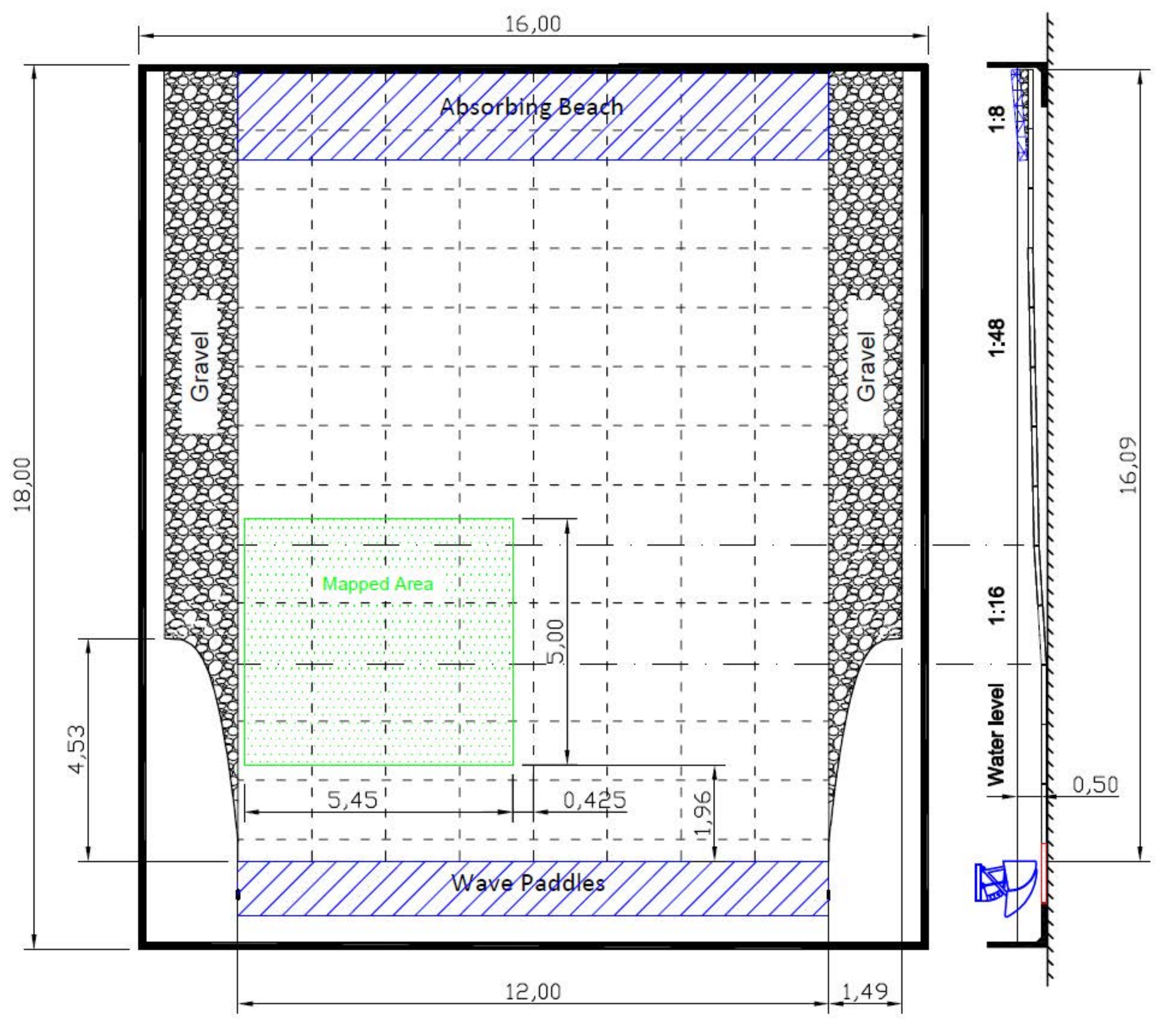


Figure Captions

Figure 1.1: Layout and bathymetric profile of the original wave basin (2010) including the position of the large and small operation areas used for assessment of performance.

Figure 2.1: Layout of different transition panel configurations which form part of the optimisation study carried out using the MIKE $21 \mathrm{BW}$ model.

Figure 2.2: Standard deviation of wave amplitude recorded in the small ( $5 \mathrm{~m} \times 5 \mathrm{~m})$ operation area for different transition panel configurations. Results are for waves of $1 \mathrm{~s}$ wave period and $12 \mathrm{~mm}$ wave amplitude.

Figure 2.3: Comparison of wave disturbance in terms of significant wave height $\left(\mathrm{H}_{\mathrm{mo}}\right)$ calculated for the original configuration and the new curved transition panels using the MIKE $21 \mathrm{BW}$ model within the entire numerical model domain for incident waves of $1 \mathrm{~s}$ wave period, $12 \mathrm{~mm}$ amplitude and $0^{\circ}$, $15^{\circ}$ and $25^{\circ}$ angles of incidence.

Figure 2.4: Sketches of different passive wave absorbers beach arrangements

Figure 3.1: Spatial variability of wave climate for the original configuration and the new wave basin based on the bias index for wave amplitude. Bias index is calculated from experimental results for the $0.625 \mathrm{~Hz}, 0.875 \mathrm{~Hz}$ and $1.125 \mathrm{~Hz}$ frequency components of the polychromatic wave condition. In this figure $x=0$ refers to the transverse mid-point of the wave basin and $y=0$ refers to the longitudinal position of the wave paddles.

Figure 3.2: Probability distribution of normalised wave amplitude for each frequency component in the polychromatic wave condition for both the original and revised wave basin configurations.

Figure 3.3: Reflection coeffients (KR) for monochromatic waves of different wave amplitudes. Three individual results are obtained for each wave condition by using a different set of three wave probes to calculate KR (black dots). The mean value for each wave condition is indicated with the blue symbols. The average KR for all wave frequencies and amplitudes is indicated by the dotted line.

Figure 4.1: Current Layout and bathymetric profile of the Queen's University 3D coastal wave basin following design modifications. 


\begin{tabular}{|c|c|c|c|}
\hline $\begin{array}{c}\text { Frequency } \\
(\mathrm{Hz})\end{array}$ & $\begin{array}{c}\text { Wave Period } \\
(\mathrm{s})\end{array}$ & $\begin{array}{c}\text { Amplitude } \\
(\mathrm{mm})\end{array}$ & $\begin{array}{c}\text { Wavelength } \\
(\mathrm{m})\end{array}$ \\
\hline 0.625 & 1.600 & 2.00 & 3.07 \\
\hline 0.750 & 1.333 & 3.58 & 2.40 \\
\hline 0.875 & 1.142 & 6.83 & 1.90 \\
\hline 1.000 & 1.000 & 12.14 & 1.51 \\
\hline 1.125 & 0.889 & 7.96 & 1.22 \\
\hline 1.250 & 0.800 & 5.63 & 1.00 \\
\hline 1.375 & 0.727 & 3.00 & 0.82 \\
\hline
\end{tabular}

Table 3.1: Wave component properties for the wave packet used for mapping the improved wave basin (water depth = $500 \mathrm{~mm}$ ) 